\title{
Harms and Wrongs in Epistemic Practice
}

How we engage in epistemic practice, including our methods of knowledge acquisition and transmission, the personal traits that help or hinder these activities, and the social institutions that facilitate or impede them, is of central importance to our lives as individuals and as participants in social and political activities. Traditionally, Anglophone epistemology has tended to neglect the various ways in which these practices go wrong, and the epistemic, moral, and political harms and wrongs that follow. In the past decade, however, there has been a turn towards the non-ideal in epistemology. This volume gathers new works by emerging and world-leading scholars on a significant cross section of themes in non-ideal epistemology. Articles focus on topics including intellectual vices, epistemic injustices, interpersonal epistemic practices, and applied epistemology. In addition to exploring the various ways in which epistemic practices go wrong at the level of both individual agents and social structures, the papers gathered herein discuss how these problems are related, and how they may be addressed.

\section{Contributors}

Alison Bailey, Olivia Bailey, Simon Barker, Heather Battaly, Havi Carel, Quassim Cassam, Charlie Crerar, Miranda Fricker, Trystan S. Goetze, Heidi Grasswick, Keith Harris, Casey Rebecca Johnson, Ian James Kidd, and Alessandra Tanesini

\section{Cambridge Core}

For further information about this journal

please go to the journal website at:

cambridge.org/phs
CAMBRIDGE UNIVERSITY PRESS
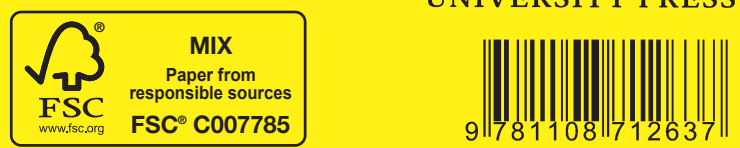